\title{
Archaeal and bacterial diversity and distribution patterns in Mediterranean vernal pools of Mexico and the western USA
}

Jorge A Mandussi Montiel-Molina ( $\boldsymbol{\nabla}$ jmontielmolina@ucmerced.edu )

University of California Merced School of Engineering https://orcid.org/0000-0001-6887-1054

Jason P Sexton

University of California Merced School of Engineering

A Carolin Frank

University of California Merced School of Engineering

Michael J Beman

University of California Merced School of Engineering

\section{Research Article}

Keywords: bacterial diversity, vernal pools, biogeographic patterns

Posted Date: June 10th, 2021

DOl: https://doi.org/10.21203/rs.3.rs-548345/v1

License: (c) (i) This work is licensed under a Creative Commons Attribution 4.0 International License.

Read Full License 


\section{Abstract}

Biogeographic patterns in microorganisms are poorly understood, despite the importance of microbial communities for a range of ecosystem processes. Our knowledge of microbial ecology and biogeography is particularly deficient in rare and threatened ecosystems. We tested for three ecological patterns in microbial diversity and community composition within ephemeral wetlands-vernal pools-located across Baja California (Mexico) and California (USA): 1) habitat filtering; 2) a latitudinal diversity gradient; and 3) distance-decay in community composition. Paired water and soil samples were collected along a latitudinal transect of vernal pools, and bacterial and archaeal communities were characterized using 16S rDNA sequencing. We identified two distinct microbial communities, with one community present in the soil matrix that included archaeal and bacterial soil taxa, and another community present in the overlying water that was dominated by common freshwater bacterial taxa. Aquatic microbial communities were more diverse in the north and displayed a significant but inverted latitudinal diversity pattern. Aquatic communities also exhibited a significant distance-decay pattern, with geographic proximity explaining $9 \%$, and precipitation explaining $16 \%$ of community variation. Collectively these results indicate greater sensitivity to spatial and environmental variation in vernal pool aquatic microbial communities than in soil microbial communities. We conclude that vernal pool aquatic microbial communities can display distribution patterns similar to those exhibited by larger organisms, but differ in some key aspects, such as the latitudinal gradient in diversity.

\section{Introduction}

Microorganisms play multiple ecological roles in terrestrial and aquatic ecosystems, from acting as symbionts and parasites to regulating biogeochemical cycles. Quantifying how microbial communities assemble and how microbial taxa are distributed across ecosystems is therefore important to our understanding of ecological equilibrium. As such, a central question in microbial ecology is the degree to which microbes follow ecological patterns displayed by 'macroorganisms' (Martiny et al, 2006, Hanson, 2012; Zhou \& Ning, 2017, Gilbert et al, 2018; Dickey et al, 2021). Traditionally, microorganisms were thought to be widely distributed in all ecosystems due to their small size and high dispersal rates, with the environment responsible for "selecting" microorganisms according to their metabolic attributes (Vinogradskij, 1889; Becking, 1934). Niche theory predicts community composition as a result of environmental filtering, and irrespective of geographic proximity (Tilman, 2004)-for example, salinity, temperature variation, oxygen limitation, and other particular conditions can strongly influence microbial community assembly in natural habitats (Zhang et al, 2019). However, it is equally clear that a combination of historical events and contemporary factors are important in determining diversity and community composition, and that microbial communities can display broad biogeographic patterns (Fierer \& Jackson, 2006; Martiny et al, 2006; Zhou \& Ning, 2017). Ultimately, microbial communities distributed within and across different ecosystems may be shaped by different assembly processes to differing degrees, providing insight into microbial community assembly in comparison to larger organisms. 
Vernal pools are ideal systems in which to examine microbial community assembly given the inherent attributes of these ecosystems. Reflecting the climatic extremes typical of "Mediterranean" ecosystems (moist and cold winters followed by hot and dry summers), vernal pools can form where water collects in shallow depressions with a high clay content and a deeper cemented layer-which prevents water percolation to the subsoil. Defined as temporary wetlands, and characterized by consecutive aquatic and terrestrial phases, vernal pools display seasonal transitions from completely flooded to totally desiccated soils (Zedler, 1987; Fig. 1). During winters with sufficient precipitation, vernal pools fill with rainwater, creating water 'islands' embedded in a surrounding terrestrial ecosystem. Vernal pools then progressively retract and eventually dry out in warmer months as evapotranspiration exceeds precipitation. Vernal pools therefore encompass both aquatic as well as soil habitats-which both vary strongly over the year, and may interact in various ways (e.g., via species that transition between the different environments, or via fluxes of carbon and nutrients). How microorganisms colonize these ecosystems, and tolerate the variations within them, directly addresses the roles of geography versus environment in affecting community assembly.

In soil, seasonal fluctuations from inundation to aridity likely create strong environmental variations. Under one extreme, saturated soils often reach anoxic conditions that may affect the distribution of microorganisms (Comeau, et at., 2012). On the other extreme, dry and hot conditions during Mediterranean summers may require adaptations-for example, desiccation-adapted microalgae may persist dormant on dry stream beds until water flow resumes (Timoner et al., 2014). During the rainy season, inundated vernal pools resemble permanent aquatic ecosystems; however, the strong seasonality of Mediterranean vernal pools shares attributes with other ephemeral aquatic ecosystems like seasonally flooded deltas, wetlands (pitlands), or floodplains (Mccarthy et al., 2003; Parolin, 2004). Freshwater ecosystems are typically inhabited by similar microbial groups (i.e., 'typical freshwater bacteria'; Zwart et al. 2002) regardless of geographic location and characteristics, but with significant spatial and temporal variation within these groups (Newton et al., 2011). Whether similar freshwater bacterial groups colonize filled vernal pools-or whether they are inhabited by more specialized groups-is unknown. In either case, these communities may be used to examine biogeographic patterns in microorganisms.

In classical ecology, the latitudinal paradigm states that diversity gradually increases from the poles to the equator following a latitudinal gradient (Keinetel, 2015; Montiel et al., 2019), and microbial ecologists have begun to study this pattern of biodiversity. The distribution of vernal pools across the California province represents a latitudinal transect of $\sim 2400$ kilometers, providing an opportunity to examine spatial patterns in diversity and community composition. In particular, vernal pools can be considered habitable islands for microbes, and microbes may show geographical patterns in diversity and community composition (Beisner et al., 2006; Finkel et al., 2012; Hayden \& Beman, 2016; Newsham et al.,2016; Schiaffino et al., 2016; Montiel et al., 2019). Unresolved for the latitudinal gradient hypothesis, is whether the gradient results from a longer, more stable period of diversification in the tropics, higher speciation rates in the tropics, or lower extinction rates in comparison with temperate regions, based on the ecology of larger organisms (Mittelbach, 2007). Microbial ecology research is still extensively needed to determine the presence and causes behind latitudinal patterns. For example, Fuhrman et al. (2008) 
detected a significant increase in planktonic marine bacterial richness from the equator to the poles in the open ocean, but with notable variability in diversity at lower latitudes. Following a transect from the tropics to the polar circles within lakes of South America and Antarctica, Schiaffino et al. (2016) detected an increase in biodiversity of microbial eukaryotes with decreasing latitude. On land, Newsham et al. (2015) also detected an increase in biodiversity of soil microfungi from colder to warmer regions along a transect from the south polar circle to the tropics. These studies indicate that both aquatic and soil microbial communities may follow latitude-diversity gradients.

Ecological studies have also observed a 'distance-decay' pattern in many natural communities, in which community similarity decreases with increasing distance between locations (Finkel et at., 2012). Distance-decay patterns can be explained by the neutral theory that predicts community composition as a result of geographic proximity, where community similarity is driven by spatially limited dispersal, independent from environmental differences between sites (Nekola and White, 1999, Hubbell, 2001); on the other hand, environmental conditions play a key role by "filtering" some taxa, and microbial communities that are closer together in space may experience similar environments. The degree to which distance-decay relationships are shaped by dispersal capabilities (spatial distance), environmental differences, or a combination of both, may differ among ecosystems. For example, community dissimilarity among microbial communities in alpine lakes can be partly explained by the distance between sites (Hayden \& Beman, 2016), whereas temporary cave-pool microbial communities are explained by the sunlight exposure and environmental properties of the water (Shabarova \& Pernthaler, 2010). For microbial communities in vernal pools of the North American continent, there is a lack of studies focusing on these ecological features.

Under the premise that microorganisms can show distribution patterns similar to those exhibited by larger organisms, we tested multiple hypotheses corresponding to specific paradigms established in classical and contemporary microbial ecology: (i) First, given the amphibious nature of other organisms inhabiting vernal pools-which have aquatic and terrestrial life cycles, and transit from soil to the water column (Zedler, 2003) -we hypothesized that microbial taxa in vernal pools may also transition between the soil matrix and water column. If this is true, we will observe measurable overlap in microbial composition between the soil matrix and the overlying water column. Alternatively, the soil matrix and water column may represent two adjacent but distinct habitat types, with distinct environmental properties that select for specific communities occupying two different niches. (ii) Considering that vernal pools are subject to strong environmental selection, we hypothesized that water saturation and desiccation events will drive shifts in community composition from flooded pools to dry pools. Niche theory (Tilman, 2004) states that the environment is the strongest driver for species to persist or recruit; in this context, moist and drought conditions may play a role in structuring microbial communities. If this is true, we expect to observe two different microbial communities in saturated versus unsaturated soils, according to the seasonalenvironmental variation in vernal pools. (iii) Considering that vernal pools are distributed latitudinally, we hypothesized the existence of a gradual increase in diversity of microorganisms along a transect from southern sites in Mexico to northern sites in the USA. (iv) In parallel, considering that vernal pools act as scattered or clustered habitat "islands" (Zedler, 2003), we hypothesized that microbial communities will 
present spatial distribution patterns reflected in the community composition from each vernal pool. Thus, a "distance-decay" pattern at local and regional scales is expected, where isolated vernal pools will have less similar microbial communities as a function of the space between pools. (v) Finally, local environmental selection is likely to drive community composition as a result of the specific environmental properties across localities. We hypothesize that environmental variation in temperature and precipitation may be significant drivers of community similarity, explaining diversity between pools, sites, and regions, regardless of spatial proximity. Alternatively, dispersal capacity of microorganisms may be important in community assembly. If this is true, we expect to observe a relationship based mostly on spatial distances.

\section{Methods}

\section{Study area and sampling design}

As a Mediterranean climate region, the study area is characterized by winter precipitation events and dry and hot summers. We considered a latitudinal transect of $\sim 1300 \mathrm{~km}$, covering part of the geographical extension of the North American Mediterranean climate regime and the distribution of its vernal pools. The sampling occurred in regions from Baja California, Mexico and California, USA (Fig. 5a), and each location varied in temperature and precipitation; temperature differences within the region range between $16^{\circ}-18^{\circ}$ Celsius, and precipitation varies depending on subregions, but overall precipitation increases with latitude (Table 1). The vernal pools studied here belong to an "archipelago complex" (i.e., clusters of pools) or solitary vernal pools, often located at flat ground on top of coastal mesas or valleys. Due to federal regulations, vernal pool soils were not possible to access in the USA. From north to south, locations were annotated alongside with their climate and geographical position: In California, USA, 1) Vina Plains, 2) Merced, 3) Santa Barbara; in Baja California, Mexico, 4) Mesa de Jesus Maria, Tijuana 5) El descanso, 6) Valle de las palmas, 7) San Antonio del Mar, 8) Medina (Colonet mesa) and 9) San Quintin.

To address our research interest regarding environmental selection and distribution patterns, we considered the first 15 centimeters from the soil surface to have a good representation of the soil microbiome (Fierer, 2003). We collected one sample of 0.2 grams of dry soil per pool in summer August 2016, representing an individual pool for a total of 11 different pools; as a counterpart, we collected 0.2 grams of "wet-soil" from the same pools, but saturated with rainfall during the winter 2017 , for a total of 11 pools. Unfortunately, some vernal pools were lost due to urbanization during our sampling period between summer and winter. Both sample types were stored in $2 \mathrm{ml}$ centrifuge tubes with dry ice before processing in the laboratory. In parallel, we also collected 100 milliliters of water per vernal pool during the winters of 2016 and 2017, for a total of 27 water samples analyzed in this study; some pools in Valle de las Palmas and San Antonio del Mar regions were sampled twice during the year 2017 corresponding to different rain events. We filtered the microorganisms from the water samples using Waltham brand $B$ filters of $0.23 \bigotimes \mathrm{m}$ pore size. After filtration the filters were preserved in lysing tubes with a sucrose EDTA lysis solution and transported to the lab for DNA extractions (Hayden and Beman, 2016). Equipment was 
sterilized in between samples with $5 \%$ bleach, $100 \%$ ethanol and rinsed with MilliQ water five times. Soil and filters were processed for DNA extractions with QIAGEN DNeasy ${ }^{\circledR}$ extraction kits. Final DNA aliquots with 50 microliters per vernal pool were diluted to a final concentration of 20 nanograms per microliter for further amplification and sequencing.

\section{Microbial Community Analysis}

We examined dry soil, wet soil and water samples via 16S rDNA amplicon sequencing targeting the regions V4 - V5 (115F[Parada]: GTGYCAGCMGCCGCGGTAA; 926R[Quince]:

GGACTACNVGGGTWTCTAAT), to capture bacterial and archaeal diversity (Beman et al, 2020). Analysis of the amplicon sequence variants (ASVs) was performed using the Qiime2 platform. Demultiplexing and pairing sequences indicated that the lowest and the highest ASV representations per sample were 714 and 66432 , respectively.

Qiime2, PASTv4.0 and R studio packages were used for statistical analyses and graphics (Bolyen et al, 2019; Hammer, 2001). Alpha diversity metrics included Richness (observed taxa), Shannon (richness/evenness), Simpson (richness/abundances), Pielou(evenness) and ACE (richness and sampling coverage). The Kruskall-Wallis test was used to analyse differences in alpha diversity metrics between dry soil, wet soils and water samples. Beta diversity was analyzed using Bray-Curtis and unweighted Unifrac metrics of community dissimilarity; environmental information was included in community analyses using PCA and NMDS ordination methods. PERMANOVA and ANOSIM (999 permutations), were used to correlate dissimilarity matrices for grouping significance. Beta diversity values were correlated ( $r$ ) with latitude and with spatial distances between sites. Mantel tests (rho) were performed to correlate taxa abundance similarity matrix values with temperature, precipitation and geographical distances matrices.

\section{Results}

\section{Microbial community patterns across vernal pools}

Analysis of microbial communities within vernal pools spread throughout California, USA and northern Baja California, Mexico revealed differences between soil samples and water samples (Fig. 2). PERMANOVA results between soil and water both showed significant differences in microbial communities (Table 2). Alpha diversity analyses of 22 soil samples, including dry soils and wet soils, was similar for all metrics of richness and abundance-suggesting that dry and wet soils host similarly diverse microbial communities despite geographic differences across sites. Soils (dry and wet) shown higher diversity values in comparison with the water column: soil-water $\mathrm{H}=18.9, \mathrm{P}=0.000013$; wet soilwater $\mathrm{H}=22.5, \mathrm{P}=0.000002$; soil-wet soil $\mathrm{H}=0.13, \mathrm{P}=0.71$ (Fig. $2 \mathrm{~b}$ ). Beta diversity analysis showed less variability in soil microbial communities in comparison with aquatic microbial communities (Fig. 2a). Soils seem to be one single habitat type defined by our taxa composition, however significant differences between dry and wet soils communities were detected with ANOSIM (Table 2). These findings suggest that conditions in vernal pools select for fairly consistent microbial communities in soils. Microbial 
adaptations to survive long periods of desiccation and the transition from flooding to desiccation could result in low variation from one phase to another (Timoner et al, 2004).

\section{Microbial taxa in soil and water}

Bacteria were present in both soils and water, but with marked differences between sample types (Fig. 3). We found 42 phyla in total, and the most abundant were Proteobacteria and Bacteroidetes. Water was dominated by a few phyla, primarily Bacteroidetes and Proteobacteria, followed by Verrucomicrobia and Actinobacteria in lower proportions. Soil was dominated by Proteobacteria, followed by Actinobacteria, Acidobacteria, Bacteroidetes, Cyanobacteria, Firmicutes, Verrucomicrobia, Planctomycetes and Gemmatimonadetes. Our analysis revealed Fusobacteria as a rare phylum associated only with water samples; rare phyla associated with soil samples were AD3, BHI80139, GOUTA4, Kazan 3B28, MVP21, OP3WS2, WS3, WS4, WS6, WWE1.

Archaea were detected almost exclusively in soils, comprising the phylum Crenarchaeota, Euryarchaeota and Pavarcheota. Archaea being mostly limited to soils suggests that aquatic archaea are less likely to inhabit vernal pool waters. At the class level, Archaeal diversity was dominated by Thaumarchaeota followed by Methanomicrobia, Thermoplasmata, MCG, and Parvarchaea (Fig. 3). Methanobacteria and Parvarchaea were found specifically in two of the most northern sites of the study, Merced and Vina Plains, suggesting geographic community variation (which we specifically evaluated below). Overall, alpha diversity metrics indicated that soils have higher diversity than water (Fig. 1b).

\section{The latitudinal diversity gradient in vernal pool microbial communities}

The general increase in biodiversity from the poles to the equator is what defines the concept of the latitudinal diversity gradient, and community composition is expected to transition gradually in sites along this gradient. We found a significant latitudinal diversity gradient in vernal pools microbes; however, this was inverted and only applied to aquatic communities (Fig. 4). In addition, only diversity metrics based on evenness (Pielou and Shannon) displayed this significant pattern.

\section{Distance decay: dispersal capabilities vs environmental selection}

Our beta diversity analysis demonstrated that aquatic communities varied among sites $\left(R^{2}=0.5625 ; \mathrm{P}<\right.$ 0.01 Fig. 5), suggesting that community isolation is driven by dispersal limitation or environmental differences between sites. To test whether dispersal limitation (geographical distance) or environmental filtering were drivers of community composition, we analysed the correlation (rho) between climatic parameters, spatial distances, and community dissimilarity indices.

Community variation was tested for correlations with mean annual temperature and precipitation. The Mantel test based on Spearman's rank correlation (permutations $=9999$ ) between mean precipitation and taxa distribution (Bray Curtis dissimilarity) showed significant correlation across all samples (r: 0.1269, $P$ $=0.0249)$. Our results showed stronger correlation with water samples only $(r: 0.4324, P=8 e-04)$, 
meaning that about $16 \%$ of the variance in water microbial communities is explained by precipitation. On the other hand, geographical distance $(r: 0.32, P=0.02)$-which addresses the influence of dispersal limitation-also significantly explained the assembly of communities (Table 3). A combination of the amount of local precipitation and geographical distance between sites was therefore significantly related to community composition. We acknowledge longer precipitation events lead to longer hydroperiods in the vernal pools, allowing aquatic microbial taxa more opportunity to disperse to some degree. Our results demonstrate that a combination of environment and spatial distances shape vernal pool microbial communities. This pattern has been found in freshwater bodies, where the existing pattern of dissimilarity (community isolation) is a product of both environmental differences and the spatial distance between sites (Shabarova \& Pernthaler, 2010; Hayden \& Beman, 2016).

\section{Discussion}

\section{Taxa identities in water}

We found that vernal pool microbial communities in water were dominated by 'typical' freshwater bacterial taxa (Zwart et al. 2002, Newton et al. 2011 ). These groups are commonly found across a wide range of freshwater ecosystems, and include various groups, especially within the Bacteroidetes and beta-proteobacteria-which were dominant overall in water samples (Fig. 2). Vernal pool waters included, for example, multiple groups of Comamonadaceae within the betaproteobacteria, which are important constituents of many freshwater ecosystems (Kasalický, 2013; Nuy et al, 2020). Actinobacteria are also common in freshwater (Newton et al. 2011), but were less abundant overall in vernal pool water. These findings suggest that common freshwater microbes are able to colonize vernal pools each year in spite of the ephemeral nature of the pools. We evaluated whether this results in significant biogeographical patterns, particularly in vernal pool water.

\section{Lack of significant biogeographic patterns in vernal pool soil communities}

A main goal of this research was to determine if microbial communities in vernal pools show distribution patterns previously recorded in other microbial systems and for larger organisms. We detected several patterns in microbial communities (e.g., a significant latitude-diversity gradient and distance-decay), but these patterns were only significant for aquatic communities. In the case of soil, our results indicate that conditions in vernal pool soils select for consistent microbial communities across distant locations. However, several factors might have also obscured our ability to detect significant patterns in soil, if present. One issue is the presence of relic DNA coming from extracellular or non- intact cells, which can account for $40-80 \%$ of prokaryotic DNA in soils, and can persist in soil for weeks to years (Lennon et al, 2017). Another possibility is that precipitation events have an impact on the microbial community by "resetting" a well established microbial community. In combination with physicochemical properties (i.e. cation exchange capacity and $\mathrm{pH}$ ), this could have a direct effect on the recovery of eDNA (Carini et al., 2016, Lennon et at., 2017). Increased sampling in future studies, and including other molecular 
techniques such as metatranscriptomic sequencing, may help reveal additional patterns, especially with soil microbial communities.

\section{Implications of vernal pool microbial communities resembling other freshwater ecosystems}

We expected that vernal pool variability (desiccation to inundation) could potentially select for unique taxa, but we found that mostly typical freshwater bacteria inhabited vernal pool water. How exactly vernal pools are populated by common freshwater taxa is an interesting question worthy of additional study and experimentation. Freshwater bacteria are notably widespread (Zwart et al, 2002), and the attributes of vernal pools may help provide insight into their broad geographic distribution and the connectivity between freshwater ecosystems via animals or air. For example, possible transport pathways could involve larger organisms that use the vernal pools as a place of rest and breeding, such as migratory birds. Additionally, rain might play an important role in transporting microorganisms (Evans et al, 2006). On the other hand, vernal pools have a cemented layer preventing interchangeable flows from subsoil to surface, which reduces the possibility of groundwater connectivity. Considering the impact of anthropogenic activities over the landscape-where some vernal pools have been transformed into stock ponds, and other human-made water reservoirs are located nearby-anthropogenic activities may also be relevant in the context of microbial distributions and its alterations. Finally, some taxa may also disperse widely by wind, and environmental constraints between habitats might shape microbial communities (Dueker et al, 2018).

\section{Inverted Latitudinal Gradient}

Some ecological explanations for such inverted gradients rely on specific interactions between taxa-for example, predation, and theories of energy around environmental systems (Morales-Castilla \& GarciaValdez, 2014). We suggest that the most possible explanation for this relationship is that vernal pools in southern latitudes have shorter periods of inundation given the lower precipitation rates compared with more northern sites. As a result, dispersal may be diminished at the southern boundary due to the absence of water bodies. Further studies should address if surrounding water bodies or precipitation provide vernal pools with freshwater taxa. Based on the limited energy hypothesis behind latitudinal diversity-which states that sunlight is directly correlated with plant productivity and species biodiversity (Morales-Castilla \& Garcia-Valdez, 2014)-another possible explanation is that higher primary production in Northern California is a reflection of longer growth periods, with inundated vernal pools lasting longer and favoring higher diversity. Moreover, the inverse prokaryotic diversity gradient observed among these study sites may be associated with eukaryotic diversity patterns, which we did not evaluate. Interestingly, at the regional scale (California vs Baja California), some bacterial phyla were unique to vernal pools from northern latitudes

\section{Conclusions}

This research is the first formal attempt to characterize and quantify microbial communities in Mediterranean-climate vernal pools in North America, providing initial insight into the microbial ecology 
of these endangered ecosystems. Overall, our study indicates that environmental selection plays an important role in defining distinct vernal pool microbial communities. Aquatic communities in vernal pools exhibit a non-traditional latitudinal diversity pattern, which may be partially explained by precipitation patterns. Dispersal limitation is important as well, which means that a combination of spatial and environmental variation affect the assembly of vernal pool microbial communities. Whether such patterns are consistent over longer time periods, and what mechanisms are involved to assemble community differences observed here, are important future research avenues. Vernal pools are wellknown for being inhabited by organisms adapted to both aquatic and terrestrial conditions (e.g., plants), with life cycles modified in order to survive shifts of inundation and total dedication in a short period of time. Occasionally this transition occurs quickly, with intermittent precipitation and evapotranspiration happening rapidly within days. Exploring these transitions at different temporal scales may provide insights about an "amphibious behavior" in microorganisms inhabiting these ecosystems-i.e., the ability to survive in both soil and water. In this case, this "taxa mixing" phenomenon is worth further study. Finally, additional spatial, temporal, and biological (e.g., plant and animal hosts and vectors) sampling may reveal new biological discoveries in these endangered vernal pool ecosystems.

\section{Declarations}

Funding: CONACyT-UCMexus 2015-2020 doctoral fellowship award; 2016 COR research funding UC Merced

Conflicts of interest/Competing interests: There is no conflict of interest

Availability of data and material: NCBI - SRA

Code availability: non applicable

Authors' contributions: All the authors contribute equally

Ethics approval: non applicable

Consent to participate: non applicable

Consent for publication: All authors agreed to publish this manuscript to Microbial Ecology

\section{References}

Becking LGMB (1934) Geobiologie of inleiding tot de milieukunde. Van Stockum Beisner BE, Peres-Neto PR, Lindström ES, et al (2006) The Role Of Environmental And Spatial Processes In Structuring Lake Communities From Bacteria To Fish. Ecology 87:2985-2991. doi: 10.1890/0012-

9658(2006)87[2985:troeas]2.0.co;2 Beman J, Vargas S, Wilson J, et al (2020) Constraining oxygen consumption by nitrite oxidation in oceanic oxygen minimum zones. doi: 10.1101/2020.05.26.115402 Bolyen E, Rideout JR, Dillon MR, et al (2019) Reproducible, interactive, scalable and extensible 
microbiome data science using QIIME 2. Nature Biotechnology 37:852-857. doi: 10.1038/s41587-0190209-9 Carini P, Marsden PJ, Leff JW, et al (2016) Relic DNA is abundant in soil and obscures estimates of soil microbial diversity. Nature Microbiology. doi: 10.1038/nmicrobiol.2016.242 Comeau AM, Harding T, Galand PE, et al (2012) Vertical distribution of microbial communities in a perennially stratified Arctic lake with saline, anoxic bottom waters. Scientific Reports. doi: 10.1038/srep00604 Dickey JR, Swenie RA, Turner SC, et al (2021) The Utility of Macroecological Rules for Microbial Biogeography. Frontiers in Ecology and Evolution. doi: 10.3389/fevo.2021.633155 Dueker ME, French S, O'Mullan GD (2018) Comparison of Bacterial Diversity in Air and Water of a Major Urban Center. Frontiers in Microbiology. doi: 10.3389/fmicb.2018.02868 Evans C, Coombes P, Dunstan R (2006) Wind, rain and bacteria: The effect of weather on the microbial composition of roof-harvested rainwater. Water Research 40:37-44. doi: 10.1016/j.watres.2005.10.034 Fierer N, Jackson RB (2006) The diversity and biogeography of soil bacterial communities. Proceedings of the National Academy of Sciences 103:626-631. doi: 10.1073/pnas.0507535103 Fierer N, Schimel JP, Holden PA (2003) Variations in microbial community composition through two soil depth profiles. Soil Biology and Biochemistry 35:167-176. doi:

10.1016/s0038-0717(02)00251-1 Finkel OM, Burch AY, Elad T, et al (2012) Distance-Decay Relationships Partially Determine Diversity Patterns of Phyllosphere Bacteria on Tamrix Trees across the Sonoran Desert. Applied and Environmental Microbiology 78:6187-6193. doi: 10.1128/aem.00888-12 Fuhrman JA, Steele JA, Hewson I, et al (2008) A latitudinal diversity gradient in planktonic marine bacteria. Proceedings of the National Academy of Sciences 105:7774-7778. doi: 10.1073/pnas.0803070105 Gilbert JA, Blaser MJ, Caporaso JG, et al (2018) Current understanding of the human microbiome. Nature Medicine 24:392-400. doi: 10.1038/nm.4517 Gilbert JA, Jansson JK, Knight R (2018) Earth Microbiome Project and Global Systems Biology. mSystems. doi: 10.1128/msystems.00217-17 Hammer $\varnothing$, Harper DAT, Ryan PD. (2001) PAST: PALEONTOLOGICAL STATISTICS SOFTWARE PACKAGE FOR EDUCATION AND DATA ANALYSIS. http://palaeo-electronica.org/2001_1/past/issue1_01.htm. Kasalický V, Jezbera J, Hahn MW, Šimek K (2013) The Diversity of the Limnohabitans Genus, an Important Group of Freshwater Bacterioplankton, by Characterization of 35 Isolated Strains. PLoS ONE. doi:

10.1371/journal.pone.0058209 Kasalický V, Jezbera J, Hahn MW, Šimek K (2013) The Diversity of the Limnohabitans Genus, an Important Group of Freshwater Bacterioplankton, by Characterization of 35 Isolated Strains. PLoS ONE. doi: 10.1371/journal.pone.0058209 Kiersztyn B, Chróst R, Kaliński T, et al (2019) Structural and functional microbial diversity along a eutrophication gradient of interconnected lakes undergoing anthropopressure. Scientific Reports. doi: 10.1038/s41598-019-47577-8 Kneitel JM (2015) Climate-driven habitat size determines the latitudinal diversity gradient in temporary ponds. Ecology. doi: 10.1890/15-1584 Lennon J, Muscarella M, Muscarella S, Lehmkuhl B (2017) How, when, and where relic DNA biases estimates of microbial diversity. doi: 10.1101/131284 Martiny JBH, Bohannan BJ, Brown JH, et al (2006) Microbial biogeography: putting microorganisms on the map. Nature Reviews Microbiology 4:102-112. doi: 10.1038/nrmicro1341 Mccarthy JM, Gumbricht T, Mccarthy T, et al (2003) Flooding Patterns of the Okavango Wetland in Botswana between 1972 and 2000. AMBIO: A Journal of the Human Environment 32:453-457. doi: 10.1579/0044-7447-32.7.453 Mittelbach GG, Schemske DW, Cornell HV, et al (2007) Evolution and the latitudinal diversity gradient: speciation, extinction and biogeography. Ecology Letters 10:315-331. doi: 10.1111/j.1461-

Page 11/19 
0248.2007.01020.x Morales-Castilla I, García-Valdés R (2014) Reverse latitudinal diversity gradients, exceptions that prove the rule? Ecosistemas 23:4-12. doi: 10.7818/ecos.2014.23-1.02 Nekola JC, White PS (1999) The distance decay of similarity in biogeography and ecology. Journal of Biogeography 26:867-878. doi: 10.1046/j.1365-2699.1999.00305.x Newton RJ, Jones SE, Eiler A, et al (2011) A Guide to the Natural History of Freshwater Lake Bacteria. Microbiology and Molecular Biology Reviews 75:1449. doi: $10.1128 / \mathrm{mmbr}$.00028-10 Nuy JK, Hoetzinger M, Hahn MW, et al (2020) Ecological Differentiation in Two Major Freshwater Bacterial Taxa Along Environmental Gradients. Frontiers in Microbiology. doi: 10.3389/fmicb.2020.00154 Parolin P, Simone OD, Haase K, et al (2004) Central Amazonian Floodplain Forests: Tree Adaptations in a Pulsing System. The Botanical Review 70:357-380. doi: 10.1663/00068101(2004)070[0357:caffta]2.0.co;2 Rusch A, Walpersdorf E, Debeer D, et al (2005) Microbial communities near the oxic/anoxic interface in the hydrothermal system of Vulcano Island, Italy. Chemical Geology 224:169-182. doi: 10.1016/j.chemgeo.2005.07.026 Schiaffino MR, Lara E, Fernández LD, et al (2016) Microbial eukaryote communities exhibit robust biogeographical patterns along a gradient of Patagonian and Antarctic lakes. Environmental Microbiology 18:5249-5264. doi: 10.1111/14622920.13566 Shabarova T, Pernthaler J (2010) Karst pools in subsurface environments: collectors of microbial diversity or temporary residence between habitat types. Environmental Microbiology 12:10611074. doi: 10.1111/j.1462-2920.2009.02151.x Tilman D (2004) Niche tradeoffs, neutrality, and community structure: A stochastic theory of resource competition, invasion, and community assembly. Proceedings of the National Academy of Sciences 101:10854-10861. doi: 10.1073/pnas.0403458101 Timoner X, Buchaca T, Acuña V, Sabater S (2014) Photosynthetic pigment changes and adaptations in biofilms in response to flow intermittency. Aquatic Sciences 76:565-578. doi: 10.1007/s00027-014-03556 Vinogradskij Sergej Nikolajevič. (1889) Recherches sur les organismes de la nitrification. Impr. Charaire Wang Y, Bradford SA, Šimůnek J (2013) Transport and fate of microorganisms in soils with preferential flow under different solution chemistry conditions. Water Resources Research 49:2424-2436. doi: 10.1002/wrcr.20174 Zedler PH (2003) Vernal pools and the concept of "isolated wetlands." Wetlands 23:597-607. doi: 10.1672/0277-5212(2003)023[0597:vpatco]2.0.co;2 Zedler PH (1987) The ecology of southern California vernal pools: a community profile. Fish and Wildlife Service, U.S. Dept. of the Interior Zhang K, Shi Y, Cui X, et al (2019) Salinity Is a Key Determinant for Soil Microbial Communities in a Desert Ecosystem. mSystems. doi: 10.1128/msystems.00225-18 Zhang X, Li L, Butcher J, et al (2019) Advancing functional and translational microbiome research using meta-omics approaches. Microbiome. doi: 10.1186/s40168-019-0767-6 Zhou J, Ning D (2017) Stochastic Community Assembly: Does It Matter in Microbial Ecology? Microbiology and Molecular Biology Reviews. doi: 10.1128/mmbr.00002-17 Zwart G, Hannen EJV, Agterveld MPK-V, et al (2003) Rapid Screening for Freshwater Bacterial Groups by Using Reverse Line Blot Hybridization. Applied and Environmental Microbiology 69:5875-5883. doi: 10.1128/aem.69.10.5875-5883.2003

\section{Tables}


Table 1

ID of the vernal pools sampled, Geoposition and 30 year annual average temperature and precipitation of vernal pool regions. Temperature (temp) is in Celsius and precipitation (precip) is in millimeters (data from BIOCLIM).

\begin{tabular}{|c|c|c|c|c|c|}
\hline Vernal pool sites & $\begin{array}{l}\text { Sample type } \\
\text { collected }\end{array}$ & Temp & Precip & Longitude & Latitude \\
\hline Vina Plains (i) & Water & 16.2 & 719 & -121.982942 & 39.901494 \\
\hline Vina Plains (ii) & Water & 16.2 & 719 & -121.983788 & 39.899747 \\
\hline Merced i & Water & 16.3 & 370 & -120.417208 & 37.376927 \\
\hline Merced ii & Water & 16.3 & 370 & -120.417668 & 37.377302 \\
\hline Merced iii & Water & 16.3 & 370 & -120.415969 & 37.375948 \\
\hline Santa Barbara i & Water & 15.2 & 468 & -119.86534 & 34.415124 \\
\hline Santa Barbara ii & Water & 15.2 & 468 & -119.866172 & 34.415841 \\
\hline Santa Barbara iii & Water & 15.2 & 468 & -119.867498 & 34.415982 \\
\hline Santa Barbara iv & Water & 15.2 & 468 & -119.868427 & 34.414142 \\
\hline Tijuana 'Jesus Maria Mesa' & $\begin{array}{l}\text { Water, wet soil, dry } \\
\text { soil }\end{array}$ & 16.9 & 277 & -116.833829 & 32.50431 \\
\hline El Descanso 'Mesa' & Water, wet soil & 16.2 & 269 & -116.871812 & 32.177932 \\
\hline (囚)Valle De Las Palmas i & Dry soil & 16.6 & 282 & -116.73994 & 32.39779 \\
\hline (囚)Valle De Las Palmas ii & Dry soil & 16.6 & 282 & -116.74147 & 32.39682 \\
\hline Valle De Las Palmas (iii) & Water, wet soil & 16.3 & 340 & -116.64541 & 32.36915 \\
\hline Valle De Las Palmas (iv) & $\begin{array}{l}\text { Water, wet soil, dry } \\
\text { soil }\end{array}$ & 16.3 & 340 & -116.64582 & 32.36913 \\
\hline Valle De Las Palmas (v) & $\begin{array}{l}\text { Water, wet soil, dry } \\
\text { soil }\end{array}$ & 16.3 & 340 & -116.64631 & 32.36937 \\
\hline San Antonio del Mar i & $\begin{array}{l}\text { Water, wet soil, dry } \\
\text { soil }\end{array}$ & 16.6 & 242 & -116.28739 & 31.09416 \\
\hline San Antonio del Mar ii & $\begin{array}{l}\text { Water, wet soil, dry } \\
\text { soil }\end{array}$ & 16.6 & 242 & -116.28722 & 31.09355 \\
\hline San Antonio del Mar iii & $\begin{array}{l}\text { Water, wet soil, dry } \\
\text { soil }\end{array}$ & 16.6 & 242 & -116.28787 & 31.09249 \\
\hline San Antonio del Mar iv & Dry soil & 16.6 & 242 & -116.29275 & 31.05852 \\
\hline 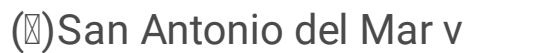 & Dry soil & 16.6 & 242 & -116.293954 & 31.027036 \\
\hline
\end{tabular}




\begin{tabular}{|llllll|}
\hline Vernal pool sites & $\begin{array}{l}\text { Sample type } \\
\text { collected }\end{array}$ & Temp & Precip & Longitude & Latitude \\
\hline $\begin{array}{l}(\bigotimes) \text { San Antonio del Mar vi } \\
\text { Medina i (Colonet mesa) }\end{array}$ & Dry soil & 16.6 & 242 & -116.293954 & 31.01739 \\
\hline Medina ii (Colonet mesa) & Water, wet soil & 16.6 & 242 & -116.282222 & 31.030835 \\
\hline Medina iii (Colonet mesa) & Water, wet soil & 16.6 & 242 & -116.283296 & 31.030569 \\
\hline $\begin{array}{l}\text { San Quintin 'Cerro las } \\
\text { Torres' }\end{array}$ & Water, wet soil & 18.9 & 179 & -115.914153 & 30.584009 \\
\hline
\end{tabular}

Table 2

Sample type group significance by Permutation analysis of variance (PERMANOVA) and Analysis of similitud (ANOSIM) between soi, wet soil and water.

\begin{tabular}{|llll|}
\hline $\begin{array}{l}\text { PERMANOVA } \\
\text { (bray-curtis) }\end{array}$ & 2 groups determined & $R=0.227$ & $P=0.001$ \\
\hline $\begin{array}{l}\text { PERMANOVA } \\
\text { (Unweighted-Unifrac) }\end{array}$ & 2 groups determined & $R=0.158747$ & $P=0.001$ \\
\hline ANOSIM & Soil - water & Wet soil - soil & Water - wet soil \\
\hline Bray-curtis & $R=0.98, p=0.001$ & $R=0.21, p=0.002$ & $R=0.97, p=0.001$ \\
\hline Unweighted-Unifrac & $R=0.89, p=0.001$ & $R=0.28, p=0.001$ & $R=0.90, p=0.001$ \\
\hline
\end{tabular}

A

Table 3

Mantel test summary: Correlation between similarity matrix based on total abundances of microbial taxa, and precipitation or geographical distances (spatial distances)

\begin{tabular}{|llll|}
\hline Matrix analysed & (rho) & Significance $P$ & Permutations \\
\hline precipitation/total.abund & r: 0.1269 & $\mathrm{P}=0.0249$ & 9999 \\
precipitation/water.abund & r: 0.4324 & $\mathrm{P}=8 \mathrm{e}-04$ & 9999 \\
\hline geographical.distance/water.abund & r: 0.3203 & $\mathrm{P}=0.0203$ & 9999 \\
\hline
\end{tabular}

\section{Figures}




\section{a) Geomorphology}

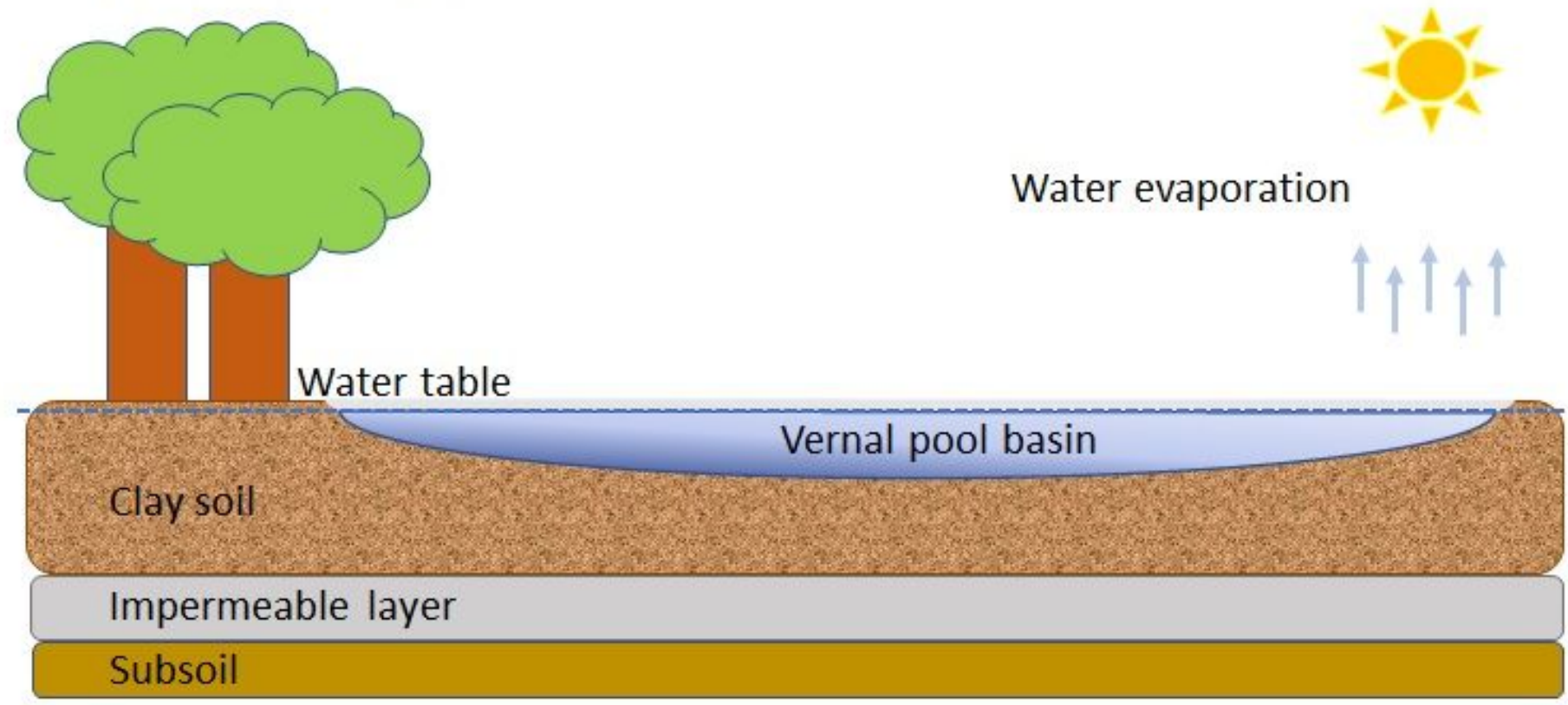

b) Aquatic phase

c) Terrestrial phase

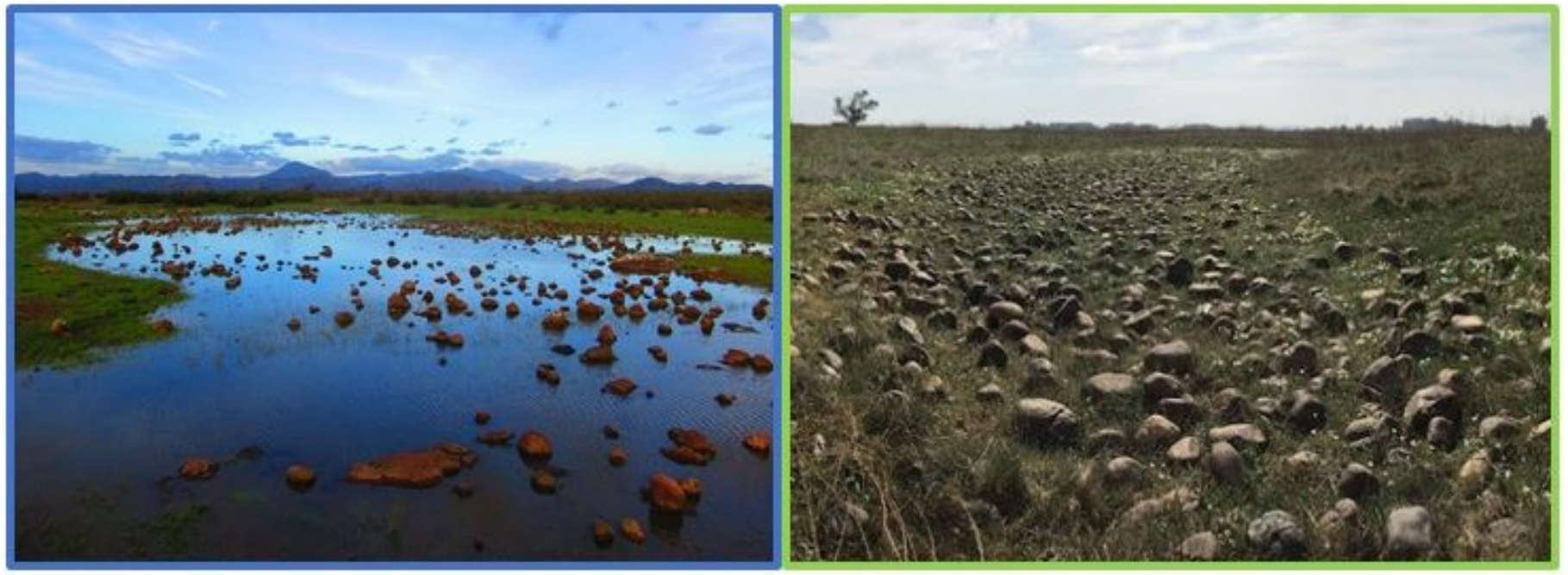

\section{Figure 1}

Physical attributes and climate create Vernal pools - temporary wetlands with contrasting phases. a) Vernal pool general geomorphology, b) aquatic phase, characterized by flooding and soil saturation and, c) terrestrial phase, characterized by water evaporation and subsequent desiccation 

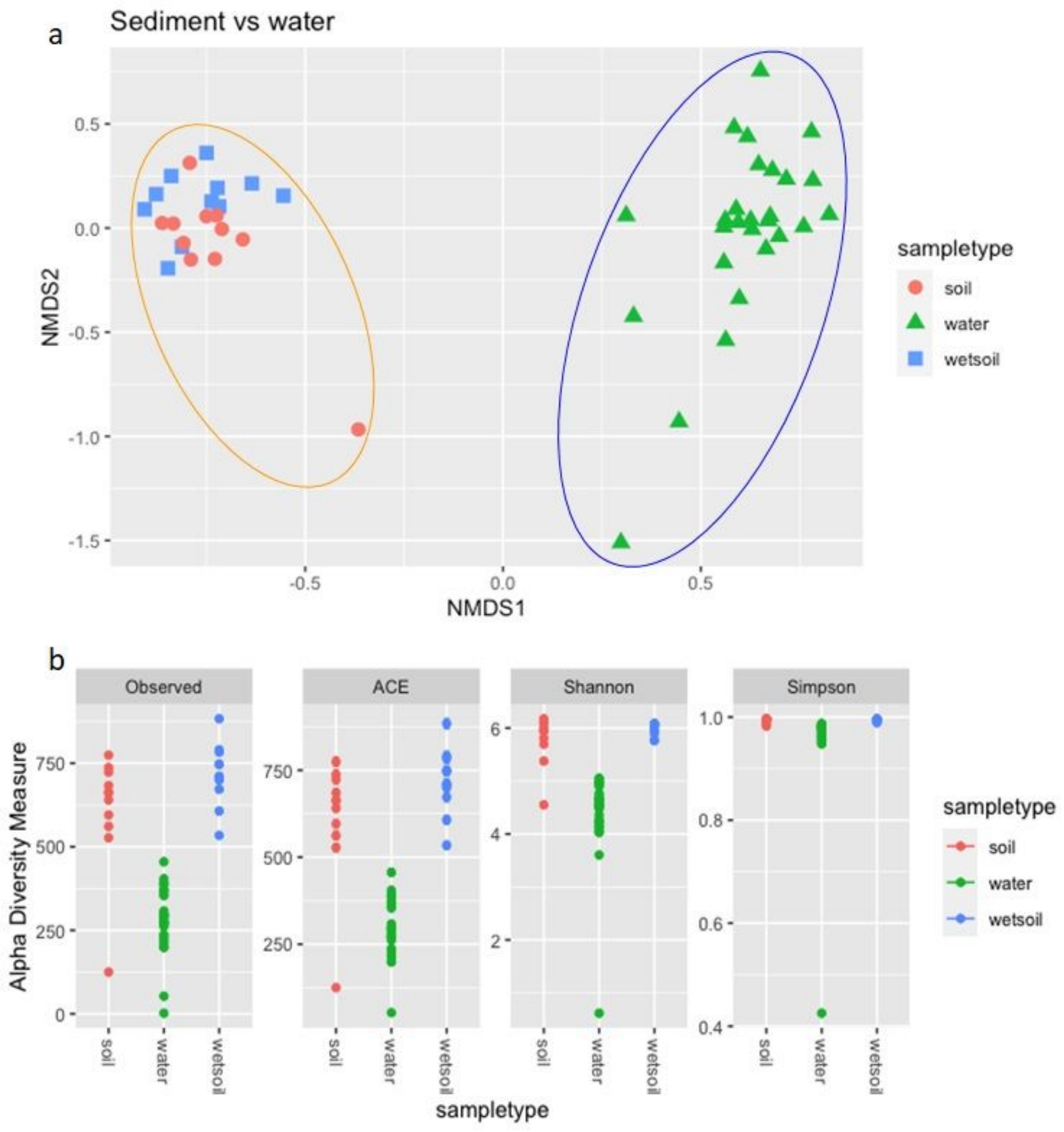

Figure 2

a) Beta Diversity: NMDS ordination analysis of microbial communities based on Bray-Curtis dissimilarity coefficients, from soils and water samples appear more homogeneous that water samples. b) Alpha diversity: Observed (observed richness), ACE (Abundance-based Coverage Estimator), Shannon and Simpson indexes. 


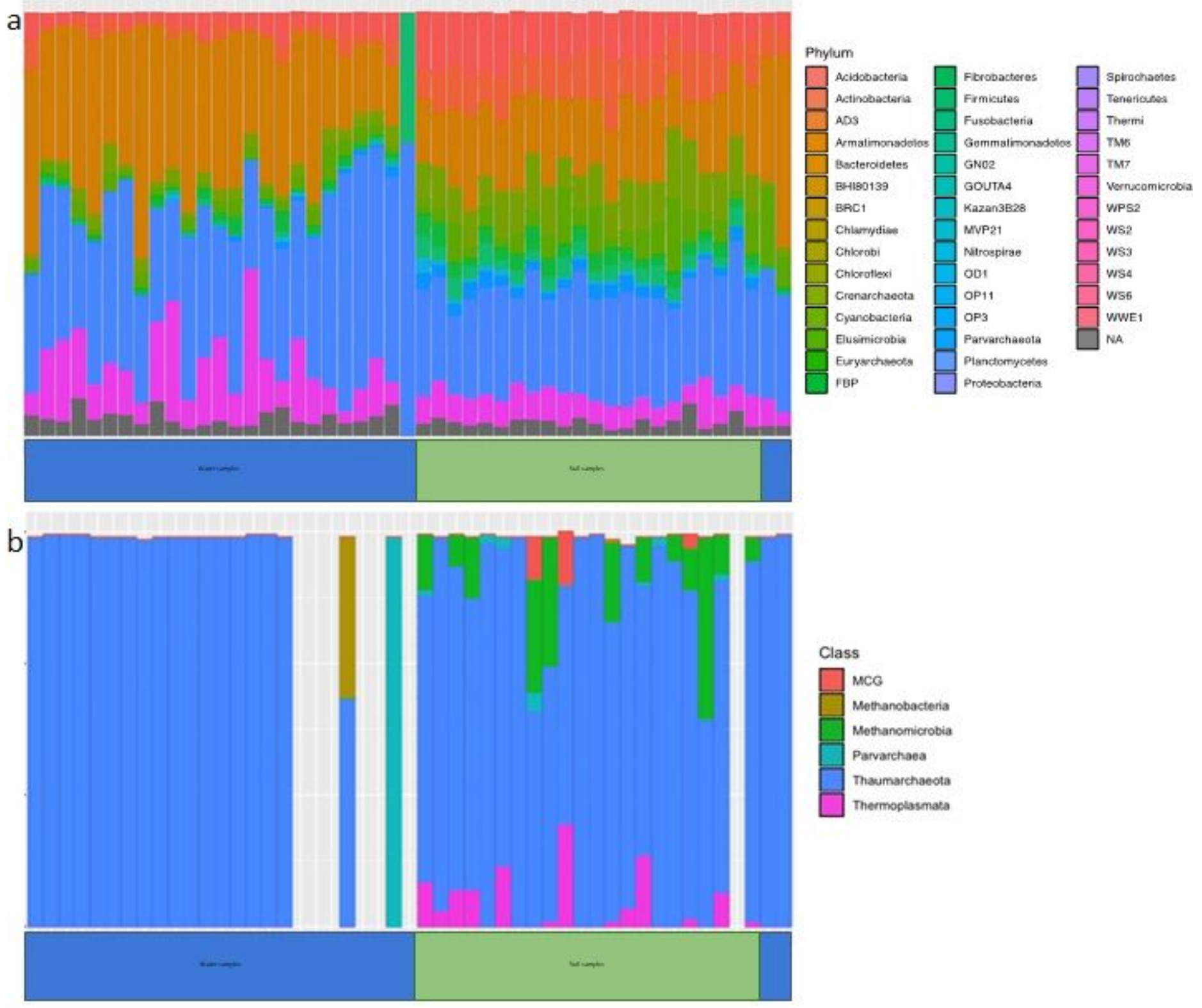

Figure 3

Bacterial and Archaeal diversity profile for water and soil samples: a) Bacterial taxa at phylum level, b) Archaeal taxa at class level. 
a) Vernal pool region and latitudinal extension

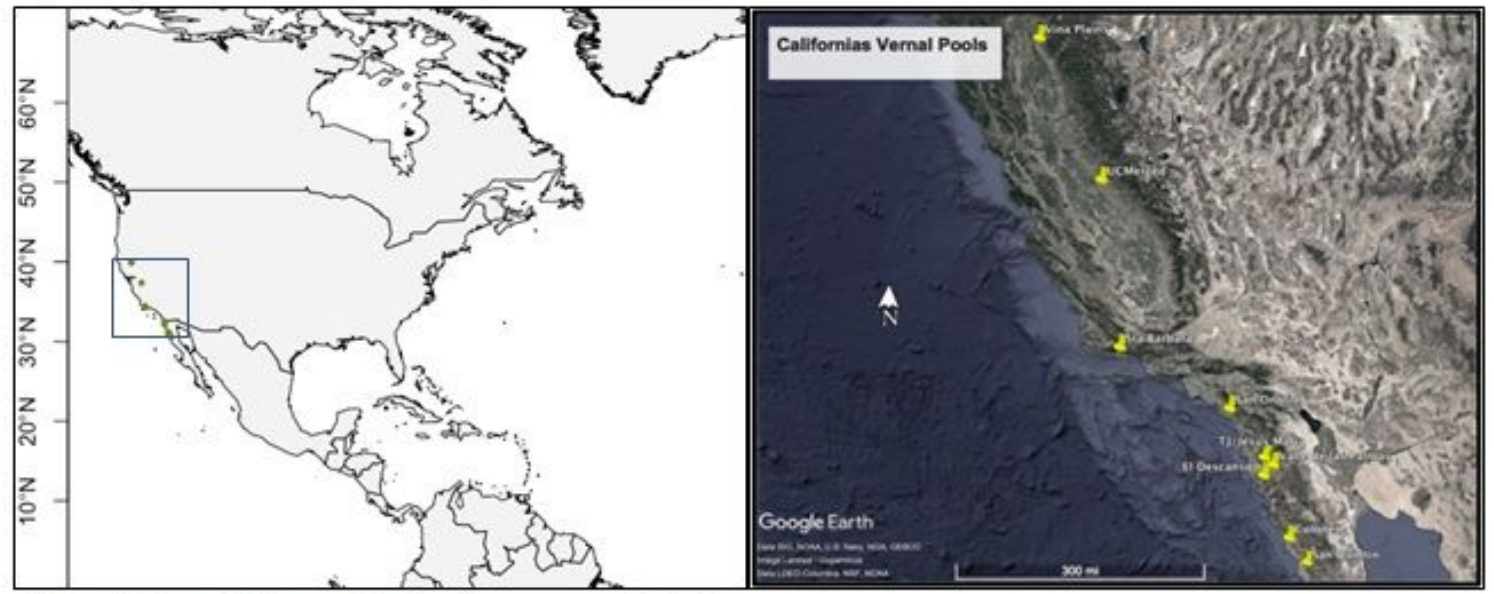

b) Correlation model (Pearson r) for diversity evenness and latitude

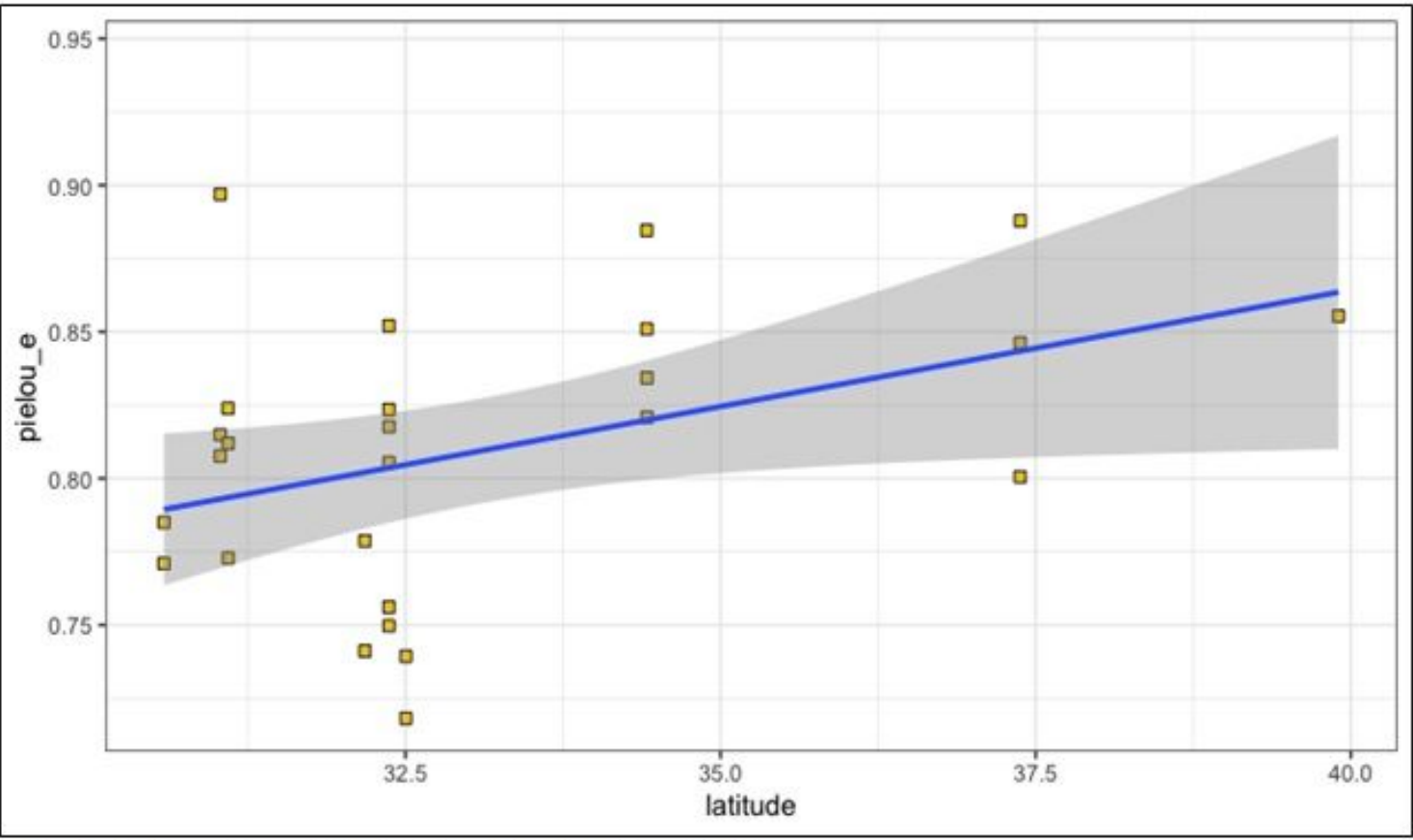

c) Synthesis of correlation coefficients between diversity metrics and latitude

\begin{tabular}{|l|l|l|l|l|}
\hline & OTU's richness & Shannon & Pielou & Ace \\
\hline Significance $p$ & 0.95 & 0.055 & 0.036 & 0.785 \\
\hline Distribution t & -0.054941 & 2.0131 & 2.2114 & -0.27562 \\
\hline Pearson's coef & -0.01121413 & 0.38 & 0.411 & -0.05617155 \\
\hline
\end{tabular}

\section{Figure 4}

Latitudinal gradient of microbial diversity: a) Latitudinal distribution of vernal pools; b) Pearson correlation model for microbial diversity based on Pielou evenness index; c) Pearson correlation coefficients for the relationship between microbial diversity and latitude coordinates. 


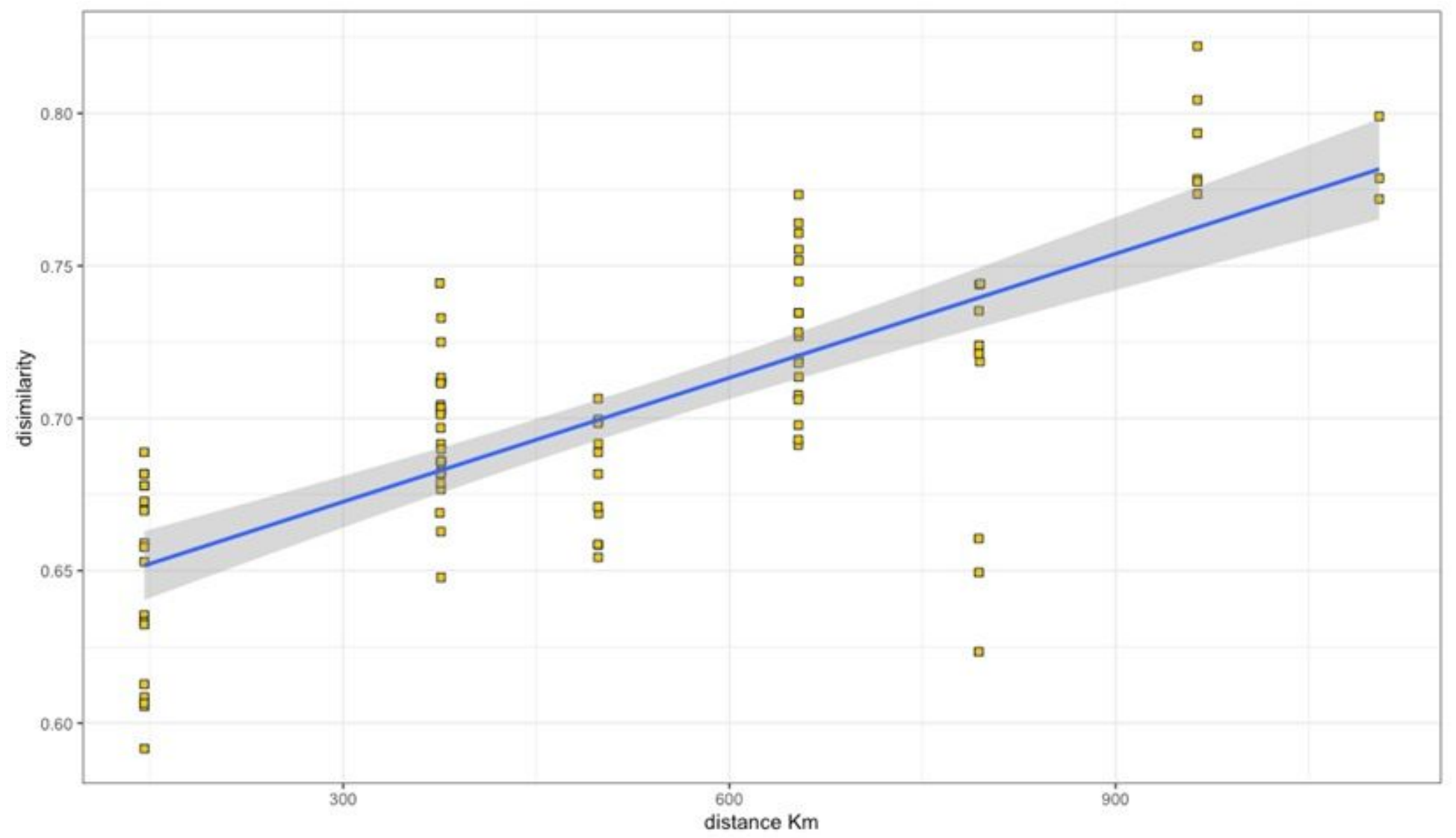

Figure 5

Distance decay model indicating dissimilarity as a function of distance between sites; points represent a specific value given by the Bray-Curtis dissimilarity index between two vernal pool microbial communities at varied spatial distances 